\title{
Perinatal Outcomes Among Venezuelan Immigrants in Colombia: A Cross-Sectional Study
}

\author{
Lina Garnica-Rosas ${ }^{1}\left[\right.$ ] Adriana Granich-Armenta ${ }^{2} \cdot$ German Guerra y Guerra $^{3} \cdot$ Mario Sánchez-Dominguez $^{3}$. \\ Hector Lamadrid-Figueroa ${ }^{2}(\mathbb{B}$
}

Accepted: 29 June 2021 / Published online: 7 August 2021

(c) The Author(s), under exclusive licence to Springer Science+Business Media, LLC, part of Springer Nature 2021

\begin{abstract}
In the last decade, Venezuela suffers a humanitarian crisis, leading to massive emigration. One of the most vulnerable migrants' groups is pregnant women. We analyzed the perinatal outcomes of Venezuelan migrants in Colombia and identified if migration was associated with perinatal outcomes. Birth data were obtained from the 2017 Colombian national birth registry (1085 births in migrants and 654,829 in Colombians). Logistic and linear regression models were used to identify the association between the demographic, obstetric and neonatal characteristics with premature birth (PB), low birth weight (LBW), 1-min, and 5-min Apgar score. Venezuelan were more likely to have newborns with LBW, lower Apgar scores at 1-min and 5-min in comparison to Colombians. Furthermore, a difference was observed in the low health insurance coverage and antenatal care visits among Venezuelan in comparison to natives. Access to health care services for the migrants is desirable for the improvement of perinatal health conditions.
\end{abstract}

Keywords Human Migration · Refugee $\cdot$ Premature birth $\cdot$ Low Birth Weight $\cdot$ Apgar Score

\section{Introduction}

During the last decade, Venezuela has faced a severe political and socioeconomic crisis. The country is marked by hyperinflation, insecurity, health system disruption, and lack of basic supplies such as food, medicines and vaccines [1]. This crisis has led to a massive emigration flow, more than three million Venezuelans have been displaced from their homes and fled into other countries, particularly to the boarding countries [2]. This migration is classified by the International Organization for Migration (IOM) as a refugee crisis, due to a large number of displaced migrants in

Hector Lamadrid-Figueroa

hlamadrid@insp.mx

1 Institute of Tropical Medicine and International Health, Charité Universitätsmedizin, Berlin, Germany

2 Department of Perinatal Health, National Institute of Public Health, Mexico Av. Universidad 655 Col. Santa María Ahuacatitlán Cuernavaca, CP 62100 Cuernavaca, Morelos, Mexico

3 Department of Health Systems Research, National Institute of Public Health, Cuernavaca, Mexico a short period, their vulnerability in living conditions and the human rights disruption in their own home country [3].

According to census data of April 2020, Colombia have received an estimate of 1,788,380 Venezuelans [4]. The host country has made several efforts to integrate the new immigrants into the Colombian system. However, they face multiple barriers including high living costs, inadequate housing conditions, lack of work, social discrimination, food insecurity, and inability to be part of the health system. These circumstances affect their quality of life, health and overall wellbeing [5].

Among this population, one of the most vulnerable groups is pregnant women, requiring social, economic and health support to assure healthy nutrition, medical care, expecting a positive perinatal and maternal result. Though, during the migration process, the provision of these conditions might be limited. It was estimated that nearly 8,209 pregnant Venezuelan women had entered Colombia by mid-2018.

Given the increase of the Venezuelan migratory phenomenon and the challenges migrants have to face, the Colombian government generated two main initiatives to provide health care. The first initiative enabled health services access for regular migrants, and comprehensive care for pregnant women and children less than a year old, independently of 
their migratory status; while irregular migrants can only access emergency services. [6] The second strategy outlined investment in health services, humanitarian needs including water, sanitation and hygiene, resources for education, and employment opportunities [7].

Furthermore, international migration entities and NGOs have coordinated with local authorities to support the government and the migrant population in special settings along within the country [7].

Although this healthcare provision to pregnant women, undocumented women face several administrative barriers to obtaining health coverage. As a result, they experience poor access to health services and sub-optimal conditions to secure the correct antenatal, labor and postnatal follow-up [8]. This situation might cause poorer perinatal and maternal outcomes in comparison with native Colombian women.

Previous studies have shown that migration is associated with adverse perinatal outcomes worldwide [9-11]. However, in Colombia, it is the first time in decades that health care providers face the effects of the massive migration flow. There is a knowledge gap regarding the consequences of migration among pregnant women and their offspring. Our aim is to evaluate the perinatal outcomes of newborns Venezuelan women in comparison with a native population focus on three relevant perinatal outcomes: premature birth (PB), low birth weight (LBW) and Apgar score, to assess the extent to which migration associates with adverse perinatal health.

\section{Methods}

\section{Data Collection}

A retrospective, cross sectional study was conducted. The data from the Colombian national births registry, corresponds to the live births occurred in Colombia between January 1 st to December 31 st, 2017, of which the vast majority occurred in 1563 health facilities [12].

Access to data was provided by the DANE (acronym in Spanish for Departamento Administrativo Nacional de Estadística-National Administrative Department of Statistics). In general, Colombian's vital statistics data consist of records filled by health workers that compile information from a required individual patient in the institution where the birth was attended. The form must be submitted for every newborn. At the country level, the estimation of under-reporting percentage is low, since the majority (98\%) of the deliveries occurred in health facilities [12].

\section{Variables Definition}

We created the main exposure variable called "mother's origin", obtained from the original variable "country of habitual residence reported for the mother". This variable was categorized by countries; in this case, "Colombia" and "Venezuela" were the most frequent answers. We considered the migration status was adequately defined by this variable, as it is likely that the pregnant women had their residence in Venezuela, and moved to Colombia to receive the labor and birth attention. Births from mothers residing in countries other than Colombia and Venezuela and any births certified as a newborn born before 24 weeks and/or less than $499 \mathrm{~g}$ were excluded.

Outcome variables were: gestational age at birth, birth weight, and Apgar score. Gestational age at birth was defined as the number of complete gestational weeks at the birth time; the exact number of completed weeks is set by the person who certifies the birth: medical doctor, nurse, community health worker or midwife. PB was considered a birth that occurred less than 36 gestational weeks. Following the WHO definition, the variable LBW was defined as the newborns with birth weight less than $2499 \mathrm{~g}$ [13]. The Apgar score was calculated for minute 1 and 5, considering a scale from 0 to 10 [14]. Demographic covariates included from the dataset were: maternal age, marital status, schooling, health insurance, and the birth region. Obstetric covariates were: multiple births, mode of birth, interbirth period, number of previous pregnancies, newborn's sex and number of antenatal visits.

\section{Data Analysis}

The statistical analysis was performed in four stages. ( $i$ ) assessment of the database to evaluate missing values and data out of range. (ii) Descriptive analysis to calculate means, standard deviations and proportions for numerical variables, and number of cases for categorical variables. (iii) bivariate analysis a chi-square was calculated to assess the association between the perinatal outcomes and the mother's origin variable and other clinical characteristics. (iv) multivariable analysis included the logistic regression analysis for bivariate outcomes (model 1: PB and model 2: LBW). The strength of association between each co-variable and the outcome was estimated and expressed as an Odds Ratio (OR) with a 95\% confidence interval (95\% CI). An additional analysis was performed, through simple and multiple linear regression analysis for continuous outcomes (model 1: 1-min Apgar score and model 2: 5-min Apgar score). Beta coefficients were used to determine the magnitude of association for 
each independent variable. We selected the covariates to be included in the models through a two-stage approach; the first stage was the inclusion of the variables based on theoretical literature review that are considered to be influence factors on perinatal outcomes such as mother's origin, maternal age, maternal education, number of previous pregnancies, interbirth period and multiple birth. The second stage was the inclusion of the covariates with a statistical significance into the model which included marital status, birth region, newborn's sex and mode of birth. Covariates that were intermediate in the causal pathway between mother's origin and the outcomes -such as health insurance coverage and antenatal visits-were excluded to avoid overfitting and underestimation of the effect of migration. Finally, routine diagnostics of the models were performed. In the case of the linear regression model heteroscedasticity was identified, thus the models were re-fitted using robust standard errors [15]. Adjusting the models for clustering at the health facility level was considered but decided against as there was no sampling stage at the facility level and the within-cluster correlation of the mother's origin variable was quite low $(\mathrm{ICC}=0.040 ; 95 \%$ CI: 0.033, 0.047). [16]

All the statistical tests were performed at a level of statistical significance of $p<0.05$. Since less than $7 \%$ of the data was missing, the available case analysis (listwise deletion method) was used to handle the missing data. All analyses were performed in STATA statistical software Version 15.1.

The current study was approved by the Ethics committee from the National Institute of Public Health (Mexico).

\section{Results}

The data base included 656,704 live births occurred in Colombia between January 1st and December 31st, 2017. From the total sample, 110 births were excluded because the country of habitual residence reported for the mother was not Colombia or Venezuela. In addition 680 births were not selected because the birth occurred before the $24^{\text {th }}$ week of gestation and/or the birthweight was less than $499 \mathrm{~g}$. Therefore, 655,914 births were included; 644,725 (98.3\%) singleton births and 11,189 (1.7\%) multiple births. The totality was classified by the mother's origin, being $654,829(99.83 \%)$ from Colombia and $1,085(0.16 \%)$ from Venezuela. The percentage of missing values was less than $7 \%$ in each variable. The study population characteristics are shown in Table 1.

The comparison of demographic factors between Colombian and Venezuelan women showed that the mean age of Venezuelan women was $24.29 \pm 5.72$ and for Colombian women it was $25.46 \pm 6.54$. Also, more than half Colombian and Venezuelan women completed secondary schooling, however it was a higher percentage of women with low schooling in the group of Venezuelan women (19.9\% vs. $14.3 \%)$.

Out of all Venezuelan women, $86.4 \%$ reported not having health insurance in comparison to the $2.5 \%$ Colombian women. Venezuelan showed a mean of 3.35 prenatal visits during their pregnancy, in contrast to native women mean of 6.37. The Venezuelan women's births occurred predominantly in the Caribbean and Islands region (48.66\%), followed by the Oriental region (32.53\%) and Bogotá/Cundinamarca (14.29\%).

The mean gestational age at birth was $38.21 \pm 2.17$ weeks for Venezuelan group, similar to $38.33 \pm 1.80$ weeks in Colombian births. Among the categorical groups, the prevalence of PB was slightly higher among Venezuelan births (10.7\% vs $9.35 \%)$; however, this difference was not statistically significant. Likewise, the LBW prevalence was not significantly different between the two groups, being only marginally higher in Venezuelan births (10.1\% vs. 9\%). Lastly, the 1-min Apgar and 5-min Apgar score evaluation had a similar mean in both groups (Table 2).

Unadjusted and adjusted logistic regressions were performed to assess the association among mother's origin and bivariate perinatal outcomes. According to the PB outcome showed in model 1, there was not a statistically significant difference between the two groups, neither before nor after the potential confounders' adjustment of maternal age, education level, marital status, number of previous pregnancies, interbirth period, region, multiple birth, mode of birth and newborn's sex (crude OR 1.16; 95\% CI 0.95-1.40) (adjusted OR 1.22; 95\% CI, 0.98-1.51) (Table 3).

Regarding the LBW outcome, the adjusted regression model revealed that Venezuelans were $27 \%$ more likely to have newborns with low birth weight, in comparison to Colombians (adjusted OR 1.27 95\% CI, 1.01-1.58) after the inclusion of potential confounders.

Venezuelan women had a negative association with a decreased Apgar score level at $1 \mathrm{~min}$ in the raw model $(\beta=-0.14 ; 95 \% \mathrm{CI}:-0.19 ;-0.09)$. Upon adjustment for maternal age, education level, marital status, number of pregnancies, interbirth period, region of birth, multiple birth, mode of birth and newborn's sex, the coefficient decreased, but remained statistically significant $(\beta=-0.085 ;$ 95\%CI: $-0.146 ;-0.025)$ (Table 4$)$.

For the 5-min Apgar score, Venezuelan women had a decrease in less than 1 point of Apgar score level for the unadjusted data ( $\beta=-0.14 ; 95 \% \mathrm{CI}:-0.18--0.09$; $\mathrm{p}=<0.001)$. After the adjustment, the association remained statistically significant $(\beta=-0.127$; 95\% CI, $-0.174-0.080 ; \mathrm{p}=<0.001)$. 
Table 1 Demographic and clinical characteristics of National Births in Colombia, 2017

\begin{tabular}{|c|c|c|c|c|c|c|c|c|c|}
\hline \multirow[t]{2}{*}{ Characteristics } & \multicolumn{4}{|c|}{ Venezuela $n=1,085(0.16 \%)$} & \multicolumn{4}{|c|}{ Colombia $\mathrm{n}=654,829(99.83 \%)$} & \multirow[t]{2}{*}{ p-value ${ }^{a}$} \\
\hline & $\mathrm{n}$ & $\%$ & Mean \pm SD & Range & $\mathrm{n}$ & $\%$ & Mean \pm SD & Range & \\
\hline Maternal age groups (years) & - & - & $24.29 \pm 5.72$ & $12-42$ & - & - & $25.46 \pm 6.54$ & $10-54$ & \\
\hline $10-19$ & 245 & 22.6 & - & - & 134,113 & 20.5 & - & - & $<0.001$ \\
\hline $20-34$ & 783 & 72.2 & - & - & 449,078 & 68.6 & - & - & - \\
\hline$\geq 35$ & 57 & 5.2 & - & - & 71,557 & 10.9 & - & - & - \\
\hline Missing values & 0 & 0 & - & - & 81 & 0.01 & - & - & - \\
\hline Maternal education & - & - & - & - & - & - & - & - & $<0.001$ \\
\hline No formal education/Primary schooling & 204 & 19.9 & - & - & 90,462 & 14.3 & - & - & - \\
\hline Secondary schooling & 669 & 65.2 & - & - & 367,282 & 58.1 & - & - & - \\
\hline Technical and technological & 73 & 7.1 & - & - & 95,828 & 15.2 & - & - & - \\
\hline Professional level and higher & 80 & 7.8 & - & - & 78,076 & 12.4 & - & - & - \\
\hline Missing values & 59 & 5.4 & - & - & 23,181 & 3.5 & - & - & - \\
\hline Marital status & - & - & - & - & - & - & - & - & 0.011 \\
\hline Married or living with the partner & 860 & 83.0 & - & - & 547,997 & 85.8 & - & - & - \\
\hline Missing values & 49 & 4.5 & - & - & 16,042 & 2.44 & - & - & - \\
\hline Number of previous pregnancies & - & - & $2.55 \pm 1.67$ & $1-11$ & - & - & $2.03 \pm 1.32$ & $1-20$ & - \\
\hline 1 & 362 & 33.4 & - & - & 286,520 & 43.8 & - & - & $<0.001$ \\
\hline $2-4$ & 595 & 54.8 & - & - & 333,938 & 51.0 & - & - & - \\
\hline$>5$ & 128 & 11.8 & - & - & 34,206 & 5.2 & - & - & - \\
\hline Missing values & 0 & 0 & - & - & 165 & 0.03 & - & - & - \\
\hline Interbirth period (months) & - & - & $51.44 \pm 35.39$ & $10.86-242.13$ & - & - & $70.23 \pm 46.63$ & $9-356.23$ & - \\
\hline$<24$ months & 134 & 12.5 & - & - & 43,425 & 6.7 & - & - & $<0.001$ \\
\hline $25-60$ months & 351 & 32.8 & - & - & 131,966 & 20.3 & - & - & - \\
\hline$>61$ months & 195 & 18.2 & - & - & 160,828 & 24.8 & - & - & - \\
\hline No previous birth & 391 & 36.5 & - & - & 312,569 & 48.2 & - & - & - \\
\hline Missing values & 14 & 1.2 & - & - & 6,041 & 0.9 & - & - & - \\
\hline Health Insurance & - & - & - & - & & & - & - & $<0.001$ \\
\hline Without health insurance & 938 & 86.4 & - & - & 16,489 & 2.5 & - & - & - \\
\hline Missing values & 0 & 0 & - & - & 120 & 0.02 & - & - & - \\
\hline Antenatal visits number & - & - & $3.35 \pm 2.60$ & $0-12$ & - & - & $6.37 \pm 2.56$ & $0-25$ & - \\
\hline $0-2$ & 433 & 39.9 & - & - & 49,942 & 7.6 & - & - & $<0.001$ \\
\hline $3-5$ & 384 & 35.4 & - & - & 166,202 & 25.4 & - & - & - \\
\hline $6-8$ & 251 & 23.1 & - & - & 326,367 & 50.0 & - & - & - \\
\hline$>9$ & 17 & 1.6 & - & - & 111,010 & 17.0 & - & - & - \\
\hline Missing values & 0 & 0 & - & - & 1,308 & 0.2 & - & - & - \\
\hline Birth region & - & - & - & - & - & - & - & - & $<0.001$ \\
\hline Bogotá and Cundinamarca & 155 & 14.3 & - & - & 129,128 & 19.7 & - & - & - \\
\hline Central & 28 & 2.6 & - & - & 146,993 & 22.4 & - & - & - \\
\hline Caribbean and Islands & 528 & 48.7 & - & - & 183,790 & 28.1 & - & - & - \\
\hline Oriental & 353 & 32.5 & - & - & 93,659 & 14.3 & - & - & - \\
\hline Pacific & 2 & 0.2 & - & - & 93,993 & 14.2 & - & - & - \\
\hline Amazonian and Orinoquia & 19 & 1.7 & - & - & 8,266 & 1.3 & - & - & - \\
\hline Missing values & 0 & 0 & - & - & 0 & 0 & - & - & - \\
\hline Mode of birth & - & - & - & - & & & - & - & 0.047 \\
\hline Vaginal birth & 624 & 57.5 & - & - & 356,839 & 54.5 & - & - & - \\
\hline Cesarean section & 461 & 42.5 & - & - & 297,816 & 45.5 & - & - & - \\
\hline Missing values & 0 & 0 & - & - & 174 & 0.02 & - & - & - \\
\hline Multiple birth & - & - & - & - & & & - & - & 0.556 \\
\hline Yes & 16 & 1.5 & - & - & 11,173 & 1.7 & - & - & - \\
\hline
\end{tabular}


Table 1 (continued)

\begin{tabular}{|c|c|c|c|c|c|c|c|c|c|}
\hline \multirow[t]{2}{*}{ Characteristics } & \multicolumn{4}{|c|}{ Venezuela $n=1,085(0.16 \%)$} & \multicolumn{4}{|c|}{ Colombia $\mathrm{n}=654,829(99.83 \%)$} & \multirow[t]{2}{*}{$\mathrm{p}$-value ${ }^{\mathrm{a}}$} \\
\hline & $\mathrm{n}$ & $\%$ & Mean \pm SD & Range & $\mathrm{n}$ & $\%$ & Mean \pm SD & Range & \\
\hline Missing values & 0 & 0 & - & - & 131 & 0.02 & - & - & - \\
\hline Newborn's sex & - & - & - & - & - & - & - & - & 0.511 \\
\hline Male infant & 567 & 52.2 & - & - & 335,623 & 51.2 & - & - & - \\
\hline Missing values & 0 & 0 & - & - & 89 & 0.01 & - & - & - \\
\hline
\end{tabular}

Divided by Venezuelan and Colombian mothers $(n=655,914)$

${ }^{a}$ The socio-demographic and clinical characteristics comparison between migrants and native women was performed using the Chi 2 test

SD: Standard Deviation

Table 2 Prevalence comparison of perinatal outcomes between Venezuelan migrants and Colombian women

\begin{tabular}{|c|c|c|c|c|c|c|c|c|c|}
\hline \multirow[t]{2}{*}{ Perinatal outcomes } & \multicolumn{4}{|c|}{ Venezuela } & \multicolumn{5}{|c|}{ Colombia } \\
\hline & $\mathrm{n}$ & $\%$ & Mean \pm SD & Range & $\mathrm{n}$ & $\%$ & Mean \pm SD & Range & p-value ${ }^{a}$ \\
\hline Gestational age at birth & & & $38.21 \pm 2.17$ & $25-42$ & & & $38.33 \pm 1.80$ & $25-44$ & \\
\hline Preterm birth $(<36$ weeks $)$ & 116 & 10.7 & & & 61,062 & 9.3 & & & 0.128 \\
\hline Missing values & 1 & 0.0 & & & 2,040 & 0.3 & & & \\
\hline Birth weight & & & $3,058 \pm 538.55$ & $560-4,800$ & & & $3,107 \pm 507.74$ & $500-6,380$ & \\
\hline Low birth weight & 110 & 10.1 & & & 59,731 & 9.0 & & & 0.186 \\
\hline Missing values & 1 & 0.0 & & & 2,034 & 0.3 & & & \\
\hline 1-min Apgar score & & & $8.05 \pm 1.03$ & & & & $8.19 \pm 0.89$ & & $<0.001$ \\
\hline Low Apgar score (0-6) & 47 & 4.3 & & & 21,616 & 3.3 & & & 0.064 \\
\hline Missing values & 3 & 0.3 & & & 6,35 & 0.1 & & & \\
\hline 5-min Apgar score & & & $9.33 \pm 0.82$ & & & & $9.47 \pm 0.74$ & & $<0.001$ \\
\hline Low Apgar score (0-6) & 12 & 1.1 & & & 4,672 & 0.7 & & & 0.131 \\
\hline Missing values & 3 & 0.3 & & & 6,330 & 0.1 & & & \\
\hline
\end{tabular}

${ }^{a}$ The perinatal outcomes comparison between migrants and native women was performed using the $\mathrm{Chi}^{2}$ test

SD: Standard Deviation

\section{Discussion}

We found an association between immigration and some adverse neonatal outcomes. Regarding the LBW, Venezuelan women were more likely to have newborns with LBW in comparison to Colombians. This finding is consistent with some studies performed in refugee populations [17-19].

The LBW among Venezuelan migrants, might be associated because of the low prevalence of antenatal care within Venezuelan women. The antenatal care might prevent LBW, because it allows (1) to monitor the gain of weight during pregnancy, (2) to promote the early detection of intrauterine growth restriction, maternal anemia and other comorbidities, and (3) to plan an individual intervention [20].

Concerning the Apgar score, we found that Venezuelan mothers were more likely to have a newborn with smaller 1-min and 5-min Apgar scores compared to Colombian mothers. Although the estimated effect on the score might appear small (around a tenth of a point decrease in the average score), due to the relatively small variability in the Apgar scores these translate into quite large increments in the risk of scoring lower than 7 for both the 1 and $5 \mathrm{~min}$ evaluations. The effect estimates from the linear model translate into a threefold increase in the risk of scoring $<7$ at $1 \mathrm{~min}$, and a twofold increase in the risk of scoring less than 7 at $5 \mathrm{~min}$. This finding is concordant with some studies [17, 21, 22]. However, it is inconsistent with other studies [23]. The lower Apgar score among the offspring of Venezuelan migrants may be linked to a lower birth weight also observed in this group [24]. Another justification might be related to the increase of anaemia among migrants. Some research has demonstrated the association between the levels of maternal haemoglobin and the Apgar score $[25,26]$.

Our study did not find a statistically significant difference for PB between the two groups. Other studies performed in similar context are in concordance [27, 28]. However it is 
Table 3 Logistic regression models: Results for the association of preterm birth and low birth weight outcomes and the exposure variables

\begin{tabular}{|c|c|c|c|c|c|c|}
\hline \multirow[t]{3}{*}{ Characteristic } & \multicolumn{3}{|c|}{ MODEL 1} & \multicolumn{3}{|c|}{ MODEL 2} \\
\hline & \multicolumn{3}{|c|}{ Preterm birth } & \multicolumn{3}{|c|}{ Low birth weight } \\
\hline & OR & $95 \% \mathrm{Cl}$ & & OR & $95 \% \mathrm{CI}$ & \\
\hline \multicolumn{7}{|l|}{ Mother's origin } \\
\hline Colombia & 1.00 & & & 1.00 & & \\
\hline Venezuela & 1.22 & 0.98 & 1.51 & 1.27 & 1.01 & 1.58 \\
\hline \multicolumn{7}{|l|}{ Maternal age groups (years) } \\
\hline $20-34$ & 1.00 & & & 1.00 & & \\
\hline $10-19$ & 1.18 & 1.15 & 1.21 & 1.11 & 1.08 & 1.14 \\
\hline$\geq 35$ & 1.16 & 1.13 & 1.19 & 1.22 & 1.19 & 1.26 \\
\hline \multicolumn{7}{|l|}{ Maternal education } \\
\hline No formal education/ Primary schooling & 1.00 & & & 1.00 & & \\
\hline Secondary schooling & 0.97 & 0.94 & 1.00 & 0.90 & 0.88 & 0.93 \\
\hline Technical and technological & 0.95 & 0.91 & 0.98 & 0.82 & 0.80 & 0.85 \\
\hline Professional level and higher & 0.86 & 0.83 & 0.90 & 0.68 & 0.66 & 0.71 \\
\hline \multicolumn{7}{|l|}{ Marital status } \\
\hline Married or living with the partner & 1.00 & & & 1.00 & & \\
\hline Single/divorced/widow & 1.14 & 1.11 & 1.17 & 1.18 & 1.15 & 1.21 \\
\hline \multicolumn{7}{|l|}{ Number of previous pregnancies } \\
\hline $2-4$ & 1.00 & & & 1.00 & & \\
\hline 1 & 0.81 & 0.78 & 0.84 & 0.89 & 0.85 & 0.92 \\
\hline$>5$ & 1.21 & 1.16 & 1.26 & 1.11 & 1.06 & 1.16 \\
\hline \multicolumn{7}{|l|}{ Interbirth period } \\
\hline $25-60$ months & 1.00 & & & 1.00 & & \\
\hline$<24$ months/ 2 years & 1.37 & 1.32 & 1.42 & 1.27 & 1.21 & 1.32 \\
\hline$>61$ months & 1.07 & 1.03 & 1.10 & 1.09 & 1.06 & 1.13 \\
\hline No previous birth & 1.37 & 1.31 & 1.43 & 1.61 & 1.55 & 1.69 \\
\hline \multicolumn{7}{|l|}{ Birth region } \\
\hline Bogotá and Cundinamarca & 1.00 & & & 1.00 & & \\
\hline Central & 0.76 & 0.75 & 0.79 & 0.61 & 0.59 & 0.63 \\
\hline Caribbean and Islands & 0.80 & 0.77 & 0.81 & 0.53 & 0.52 & 0.55 \\
\hline Oriental & 0.68 & 0.66 & 0.70 & 0.48 & 0.47 & 0.50 \\
\hline Pacific & 0.81 & 0.79 & 0.83 & 0.61 & 0.59 & 0.63 \\
\hline Amazonian and Orinoquia & 0.44 & 0.40 & 0.50 & 0.27 & 0.23 & 0.30 \\
\hline \multicolumn{7}{|l|}{ Multiple birth } \\
\hline No & 1.00 & & & 1.00 & & \\
\hline Yes & 16.36 & 15.50 & 17.26 & 19.80 & 18.74 & 20.91 \\
\hline \multicolumn{7}{|l|}{ Newborn's sex } \\
\hline Female infant & 1.00 & & & 1.00 & & \\
\hline Male infant & 0.93 & 0.91 & 0.94 & 1.21 & 1.19 & 1.23 \\
\hline \multicolumn{7}{|l|}{ Mode of birth } \\
\hline Vaginal birth & 1.00 & & & 1.00 & & \\
\hline Cesarean section & 1.73 & 1.70 & 1.76 & 1.76 & 1.73 & 1.80 \\
\hline
\end{tabular}

Models adjusted for: maternal age, education level, marital status, number of previous pregnancies, interbirth period, birth region, multiple birth, mode of birth and newborn's sex

OR (Odds Ratio) and 95\% Confidence Interval (95\% CI) contrary from some studies showed higher prevalence of PB in migrants compared to natives groups [17, 29, 30].

The most remarkable disadvantage in migrants compared to native women found in our study is the low health insurance coverage ( $2.52 \%$ vs. $86.46 \%)$, which might be one of the main factors that influence the lack of antenatal care. Venezuelan women had an average of only three antenatal care appointments, a scarce quantity when comparing to 
Table 4 Linear regression models: Results for the association of 1-min and 5-min Apgar scores and the exposure variables

\begin{tabular}{|c|c|c|c|c|c|c|}
\hline \multirow[t]{2}{*}{ Characteristic } & \multicolumn{3}{|c|}{ Model 1: 1- minute Apgar score } & \multicolumn{3}{|c|}{ Model 2: 5- minute Apgar score } \\
\hline & $\beta$ coefficient & $95 \% \mathrm{CI}$ & & $\beta$ coefficient & $95 \% \mathrm{CI}$ & \\
\hline \multicolumn{7}{|l|}{ Mother's origin } \\
\hline Colombian & 1.00 & & & 1.00 & & \\
\hline Venezuelan & -0.085 & -0.146 & -0.025 & -0.127 & -0.174 & -0.080 \\
\hline \multicolumn{7}{|l|}{ Maternal age groups (years) } \\
\hline $20-34$ & 1.00 & & & 1.00 & & \\
\hline $10-19$ & -0.020 & -0.026 & -0.013 & -0.006 & -0.011 & -0.0006 \\
\hline$\geq 35$ & -0.012 & -0.020 & -0.005 & -0.015 & -0.022 & -0.009 \\
\hline \multicolumn{7}{|l|}{ Maternal education } \\
\hline No formal education/ Primary schooling & 1.00 & & & 1.00 & & \\
\hline Secondary schooling & 0.038 & 0.031 & 0.046 & -0.004 & -0.010 & 0.0009 \\
\hline Technical and technological & 0.069 & 0.060 & 0.077 & 0.016 & 0.009 & 0.023 \\
\hline Professional level and higher & 0.147 & 0.137 & 0.156 & 0.067 & 0.060 & 0.075 \\
\hline \multicolumn{7}{|l|}{ Marital status } \\
\hline Married or living with the partner & 1.00 & & & 1.00 & & \\
\hline Single/divorced/widow & -0.047 & -0.053 & -0.040 & -0.023 & -0.029 & -0.018 \\
\hline \multicolumn{7}{|l|}{ Number of previous pregnancies } \\
\hline $2-4$ & 1.00 & & & 1.00 & & \\
\hline 1 & 0.022 & 0.011 & 0.033 & 0.025 & 0.016 & 0.034 \\
\hline$>5$ & -0.032 & -0.043 & -0.021 & -0.028 & -0.038 & -0.019 \\
\hline \multicolumn{7}{|l|}{ Interbirth period } \\
\hline $25-60$ months & 1.00 & & & 1.00 & & \\
\hline$<24$ months $/ 2$ years & -0.013 & -0.023 & -0.003 & -0.012 & -0.020 & -0.004 \\
\hline$>61$ months & -0.018 & -0.024 & -0.011 & -0.017 & -0.022 & -0.012 \\
\hline No previous birth & -0.079 & -0.091 & -0.067 & -0.066 & -0.076 & -0.056 \\
\hline \multicolumn{7}{|l|}{ Birth region } \\
\hline Bogotá and Cundinamarca & 1.00 & & & 1.00 & & \\
\hline Central & 0.078 & 0.071 & 0.084 & 0.327 & 0.321 & 0.332 \\
\hline Caribbean and Islands & 0.153 & 0.146 & 0.159 & 0.221 & 0.216 & 0.227 \\
\hline Oriental & 0.095 & 0.088 & 0.102 & 0.302 & 0.296 & 0.308 \\
\hline Pacific & 0.428 & 0.421 & 0.435 & 0.403 & 0.397 & 0.409 \\
\hline Amazonian and Orinoquía & 0.024 & 0.002 & 0.046 & 0.192 & 0.174 & 0.210 \\
\hline \multicolumn{7}{|l|}{ Multiple birth } \\
\hline No & 1.00 & & & 1.00 & & \\
\hline Yes & -0.341 & -0.369 & -0.313 & -0.325 & -0.350 & -0.300 \\
\hline \multicolumn{7}{|l|}{ Newborn’s sex } \\
\hline Female infant & 1.00 & & & 1.00 & & \\
\hline Male infant & 0.036 & 0.032 & 0.041 & 0.020 & 0.017 & 0.024 \\
\hline \multicolumn{7}{|l|}{ Mode of birth } \\
\hline Vaginal birth & 1.00 & & & 1.00 & & \\
\hline Cesarean section & -0.061 & -0.066 & -0.056 & -0.093 & -0.097 & -0.089 \\
\hline
\end{tabular}

Models adjusted for: maternal age, education level, marital status, number of previous pregnancies, interbirth period, birth region, multiple birth, mode of birth and newborn's sex

ß coefficient and 95\% Confidence Interval (95\% CI)

WHO recommendations [31]. The lack of antenatal followup in Venezuelan women can also be due to other explanations, including: (1) limited access to prenatal care in the country of origin [32], and (2) delay of medical attention seeking during the migration process for reasons such cost, travel distance to prenatal care, lack of awareness of Colombian health institutions and/or fear of miss-treatment or quality of medical care $[33,34]$. Any of these scenarios affects 
the prenatal care services provision directly and could have an impact on maternal and perinatal health. In any case, closing this enormous gap between native and migrant pregnant women could be a strong measure taken by the Colombian health system towards the improvement of prenatal outcomes and health equity promotion of migrant population in Colombia.

The main strength of this study is the use of large sample size ( $n=656,594$ births), that supports the statistical analysis results and the conclusions of the study. Many limitations were found, the main one is the lack of assessment of the migration type (long term, short term, in transit, or circular migration), and the migratory status (documented, undocumented) [35]. The absence of this information limits the analyses, considering that the social, economic, and cultural factors might differ between groups and affects the consequences in the health and wellness of this population. Furthermore, there is limited information within the database regarding the residence area or other demographic characteristics that could suggest that a specific Colombian group is undeserved or fill similar conditions of Venezuelan migrants. Therefore, it was not possible to compare these specific groups. Similar to governmental reports, our study found that the majority of Venezuelan migrants are located in Bogotá, the oriental region and the Caribbean region [36]. However, with the available official data, we could not determine if the immigrants are living in these regions or if they travel to seek medical attention to attend the deliveries. Considering the political and social situation among the humanitarian crises in Venezuela, we might assume that the migrants' main objective was to seek humanitarian support in the host country in order to fill basic needs (food, household, etc.) not specifically to find obstetrics facilities. However, due to the lack of information we could not demonstrate this statement.

An additional limitation is the lack of information on the database about the socio-economic status of migrants. This is an important limitation as it is clear that humanitarian crises cause people from different social strata to migrate and socio-economic status is likely related to perinatal outcomes. Besides, the information regarding the differences of health accessibility between migrant subgroups is limited, and thus there remains a gap of knowledge about the difference of the outcomes. Another limitation corresponds to the lack of variables such as gestational age at the 1st antenatal control, maternal nutritional status (before and after the migration process), weight gain during pregnancy, consumption of gestational supplements, intrauterine infections, anaemia, smoking status, neonatal malformations, among others.

In spite of these limitations, to our knowledge, this is the first study focused on the analysis of the perinatal health outcomes of immigrant population in Colombia. Our results also suggest that there is still a large gap to close, both in terms of knowledge and in health care access, for assessing the underlying causes of differentials between perinatal health outcomes (as expressed in the Low Birth weight and Apgar score), and the health care utilization between Colombian and immigrant Venezuelan populations.

This study included information from 2017, though the humanitarian crises is still a reality for the Venezuelan population, which has increased the migratory phenomenon during the last three years, in addition to other recent factors which might have an influence in the dynamics of the migratory process (e.g. COVID-19 pandemic). These facts call for an action to expand the available information and the development of further studies focussed on the subsequent years to observe the consequences of migration in maternal and perinatal health in Colombia. This study can set a first effort to develop further research in order to address the complex and impending health challenges faced by both the Venezuelan and Colombian society.

\section{Conclusions}

In Colombia, migration status may be an important and independent risk factor for some adverse maternal and neonatal outcomes such as low birth weight and a low 1 and $5 \mathrm{~min}$ Apgar score. The disadvantage found in health insurance coverage among the Venezuelan women could influence the occurrence of adverse perinatal outcomes, ought to insufficient antenatal care in comparison to Colombian natives. Further research is needed to enlarge the information regarding the complex migration situation in Colombia.

\section{New Contribution to the Literature}

To our knowledge, this is the first study focused on the analysis of the perinatal health outcomes of immigrant Venezuelan population in Colombia. Our study design allowed us to obtain some findings among this population, such as LBW and low 1-min and 5-min Apgar score that are consistent with previous research conducted on this type of vulnerable group in other countries. However, our results also suggest that there is still a large gap to close, both in terms of knowledge and in health care access, for assessing the underlying causes of differentials between perinatal health outcomes, and the health care utilization between Colombian and immigrant Venezuelan populations. This study can set a first effort to develop further research in order to address the complex and impending health challenges faced by both the Venezuelan and Colombian societies.

Acknowledgements This work was supported in part by DAAD (Deutscher Akademischer Austauschdienst-German Academic 
Exchange Service), and the National Institute of Public Health, Cuernavaca, Mexico grants. The funding sources had no involvement in the study design, collection, analysis and interpretation of the data, neither in the writing of the report or in the decision to submit the article for publication.

\section{References}

1. The UN Refugee Agency (UNHCR). UNHCR - Venezuela situation. 2019. https://www.unhcr.org/venezuela-emergency.html

2. The UN Refugee Agency (UNHCR). Regional refugee plan and migrant response plan for Refugees and Migrants from Venezuela. 2019. https://data2.unhcr.org/es/documents/download/67282

3. International Organization for Migration (IOM). Venezuelan Refugee and Migrant Crisis. 2020. https://www.iom.int/venez uela-refugee-and-migrant-crisis

4. Response for Venezuelans (R4V). Coordination platform for refugees and migrants from Venezuela. 2020. https://r4v.info/en/situa tions/platform

5. International Republican Institute (IRI). The Venezuelan Migration Crisis in Colombia: Challenges for the local government. 2019. https://www.iri.org/sites/default/files/colombia_report_ spanish.pdf

6. Bonilla-Tinoco LJ, Aguirre-Lemus M, Fernandez-Niño JA. Venezuelan migrant population in Colombia: health indicators in the context of the Sustainable Development Goals. F1000Research. 2020;9:684.

7. Grupo Interagencial sobre Flujos Migratorios Mixtos (GIFMM), Response for Venezuelans (R4V). Colombia - GIFMM Situational Report - April 2019. UN Refug Agency. 2019. p. 1-8. https:// data2.unhcr.org/en/documents/download/69770

8. Unidad Nacional para la Gestión del Riesgo de Desastres (UNGRD) (National Unit for Disaster Risk Management). Registro Administrativo de Migrantes Venezolanos en Colombia (Administrative Registry of Venezuelan Migrants in Colombia). 2018. https://data2.unhcr.org/en/documents/download/64101

9. Heslehurst N, Brown H, Pemu A, Coleman H, Rankin J. Perinatal health outcomes and care among asylum seekers and refugees: a systematic review of systematic reviews. BMC Med. 2018;16:89.

10. Col Madendag I, Eraslan Sahin M, Madendag Y, Sahin E, Demir $\mathrm{MB}$, Ozdemir F, et al. The effect of immigration on adverse perinatal outcomes: analysis of experiences at a Turkish tertiary hospital. Biomed Res Int. 2019;2019:2326797.

11. Bozorgmehr K, Biddle L, Preussler S, Mueller A, Szecsenyi J. Differences in pregnancy outcomes and obstetric care between asylum seeking and resident women: a cross-sectional study in a German federal state, 2010-2016. BMC Pregnancy Childbirth. 2018;18:417.

12. Departamento Administrativo Nacional de Estadística (DANE) (National Administrative Department of Statistics). Nacimientos (Births). DANE. 2017. https://www.dane.gov.co/index.php/estad isticas-por-tema/salud/nacimientos-y-defunciones/nacimientos/ nacimientos-2016

13. World Health Organization (WHO). Low birth weight. Country, regional and global estimates. 2004. https://apps.who.int/iris/bitst ream/handle/10665/43184/9280638327.pdf;sequence $=1$

14. The American College of Obstetricians and Gynecologists (ACOG). The Apgar Score. 2015. https://www.acog.org/-/media/ Committee-Opinions/Committee-on-Obstetric-Practice/co644. pdf?dmc $=1 \&$ ts $=20190626 \mathrm{~T} 0019331268$

15. White H. A Heteroskedasticity-consistent covariance matrix estimator and a direct test for Heteroskedasticity. Econometrica. 1980;48:817.
16. Abadie A, Athey, Susan Imbens, Guido Wooldridge J. When Should You Adjust Standard Errors for Clustering? 2017. p. 29. https://arxiv.org/abs/1710.02926

17. Alnuaimi K, Kassab M, Ali R, Mohammad K, Shattnawi K. Pregnancy outcomes among Syrian refugee and Jordanian women: a comparative study. Int Nurs Rev England. 2017;64:584-92.

18. Turkay Ü, Aydın Ü, Salıcı M, Çalışkan E, Terzi H, Astepe BS, et al. Comparison of pregnant Turkish women and Syrian refugees: Does living as a refugee have an unfavorable effect on pregnancy outcomes? Int J Gynaecol Obstet United States. 2020;149:160-5.

19. Reese Masterson A, Usta J, Gupta J, Ettinger AS. Assessment of reproductive health and violence against women among displaced Syrians in Lebanon. BMC Womens Health. 2014;14:25.

20. Kominiarek MA, Peaceman AM. Gestational weight gain. Am J Obstet Gynecol. 2017;217:642-51.

21. Small R, Gagnon A, Gissler M, Zeitlin J, Bennis M, Glazier $\mathrm{R}$, et al. Somali women and their pregnancy outcomes postmigration: data from six receiving countries. BJOG England. 2008;115:1630-40.

22. Cacciani L, Asole S, Polo A, Franco F, Lucchini R, De Curtis M, et al. Perinatal outcomes among immigrant mothers over two periods in a region of central Italy. BMC Public Health. 2011;11:294.

23. Gungor ES, Seval O, Ilhan G, Verit FF. Do Syrian refugees have increased risk for worser pregnancy outcomes? Results of a tertiary center in Istanbul. Turkish J Obstet Gynecol Turkey. 2018;15:23-7.

24. Phalen AG, Kirkby S, Dysart K. The 5-minute Apgar score: survival and short-term outcomes in extremely low-birth-weight infants. J Perinat Neonatal Nurs United States. 2012;26:166-71.

25. Allen LH. Anemia and iron deficiency: effects on pregnancy outcome. Am J Clin Nutr. 2000;1-3(71):1280-4.

26. Lee HS, Kim MS, Kim MH, Kim YJ, Kim WY. Iron status and its association with pregnancy outcome in Korean pregnant women. Eur J Clin Nutr England. 2006;60:1130-5.

27. Erenel H, AydoganMathyk B, Sal V, Ayhan I, Karatas S, Koc BA Clinical characteristics and pregnancy outcomes of Syrian refugees: a case-control study in a tertiary care hospital in Istanbul. Turkey Arch Gynecol Obstet Germany. 2017;295:45-50.

28. Manrique-Leal M, Barboza-Retana J. Características del control prenatal y el parto de las mujeres inmigrantes atendidas en el Hospital Dr Rafael Ángel Calderón Guardia. Acta Med Costarric. 2008;50:107-11.

29. Abu Hamad K, Abed Y, Abu HB. Risk factors associated with preterm birth in the Gaza Strip: hospital- based case control study. East Mediterr Health J. 2007;13:1132-41.

30. Ozel S, Yaman S, Kansu-Celik H, Hancerliogullari N, Balci N, Engin-Ustun Y. Obstetric outcomes among Syrian Refugees: a comparative study at a tertiary care maternity hospital in Turkey. Rev Bras Ginecol Obstet Brazil. 2018;40:673-9.

31. World Health Organization (WHO). WHO recommendations on antenatal care for a positive pregnancy experience. Geneva; 2016. p. 172. https://apps.who.int/iris/bitstream/handle/10665/250796/ 9789241549912-eng.pdf?sequence $=1$

32. Oficina del Alto Comisionado de las Naciones Unidas para los Derechos Humanos (ACNUDH) (The UN Refugee Agency). Violaciones de los derechos humanos en la República Bolivariana de Venezuela: una espiral descendente que no parece tener fin (Human rights violations in the Bolivarian Republic of Venezuela: a downward spiral that seems to have no end). 2018. https://www. ohchr.org/Documents/Countries/VE/VenezuelaReport2018_SP. pdf

33. Kandasamy T, Cherniak R, Shah R, Yudin MH, Spitzer R. Obstetric risks and outcomes of refugee women at a single centre in Toronto. J Obstet Gynaecol Can Netherlands. 2014;36:296-302. 
34. Benage M, Greenough PG, Vinck P, Omeira N, Pham P. An assessment of antenatal care among Syrian refugees in Lebanon. Confl Health. 2015;9:8.

35. International Organization for Migration (IOM). Glossary on Migration. International Migration Law N 34. Geneva; 2019. https://publications.iom.int/system/files/pdf/iml_34_glossary.pdf

36. Migración Colombia. Especial - Así ha sido la evolución de la crisis migratoria venezolana -corte agosto 31 de 2019. 2019. https:// www.migracioncolombia.gov.co/infografias/231-infografias-2019/ especial-asi-ha-sido-la-evolucion-de-la-crisis-migratoria-venez olana-corte-agosto-31-de-2019

Publisher's Note Springer Nature remains neutral with regard to jurisdictional claims in published maps and institutional affiliations. 